\title{
Evaluation of official tropical cyclone landfall forecast issued by India Meteorological Department
}

\author{
M Mohapatra*, D P Nayak, Monica Sharma, R P Sharma and B K Bandyopadhyay \\ India Meteorological Department, Mausam Bhavan, Lodi Road, New Delhi 110 003, India. \\ ${ }^{*}$ Corresponding author.e-mail: mohapatraimd@gmail.com
}

India Meteorological Department (IMD) introduced the objective tropical cyclone (TC) track forecast valid for next 24 hrs over the North Indian Ocean (NIO) in 2003. It further extended the validity period up to $72 \mathrm{hrs}$ in 2009. Here an attempt is made to evaluate the TC landfall forecast issued by IMD during 2003-2013 (11 years) by calculating the landfall point forecast error (LPE) and landfall time forecast error (LTE).

The average LPE is about 67, 95, and $124 \mathrm{~km}$ and LTE is about 4, 7, and $2 \mathrm{hrs,} \mathrm{respectively} \mathrm{for}$ 24, 48, and 72-hr forecasts over the NIO as a whole during 2009-2013. The accuracy of TC landfall forecast has been analysed with respect to basin of formation (Bay of Bengal, Arabian Sea, and NIO as a whole), specific regions of landfall, season of formation (pre-monsoon and post-monsoon seasons), intensity of TCs (cyclonic storm (CS), and severe cyclonic storm (SCS) or higher intensities) at the time of initiation of forecast and type of track of TCs (climatological/straight moving and recurving/looping type). The LPE is less over the BOB than over the AS for all forecast lengths up to $72 \mathrm{hrs}$. Similarly, the LPE is less during the post-monsoon season than during pre-monsoon season. The LPEs are less for climatologically moving/straight moving TCs than for the recurving/looping TCs.

The LPE over the NIO has decreased at the rate of about $14.5 \mathrm{~km} /$ year during 2003-2013 for 24-hr forecasts. The LTE does not show any significant improvement for 24-hr forecast during the same period. There is significant decrease in LPE and LTE during 2009-2013 compared to 2003-2008 due to the modernisation programme of IMD. The 24-hr LPE and LTE have decreased from 157.5 to $66.5 \mathrm{~km}$ and 7.8 to $4.1 \mathrm{hrs}$, respectively. However, there is still scope for further reduction in 48 and 72-hr forecast errors over the NIO to about 50 and $100 \mathrm{~km}$ respectively based on the latest technology including aircraft reconnaissance, deployment of buoys, and assimilation of more observational data from satellite and Doppler weather radars, etc., in the numerical weather prediction (NWP) models during the next five years.

\section{Introduction}

A major component of tropical cyclone (TC) motion forecasting is the routine preparation of best tracks and detailed forecast performance statistics at the end of each season. Its importance further increases, when we consider the landfalling TCs over the North Indian Ocean (NIO) and prediction of their landfall point and time due to TC hazard proneness of the region (Mohapatra et al. 2012a). Though this is a time-consuming task, it provides invaluable information on overall forecast performance and the relative performance of individual techniques. Such information is essential for (i) developing new techniques and monitoring forecast improvements resulting from new techniques and observing systems, (ii) evaluation of value addition by forecasters to guidance received from the objective aids, (iii) providing a basis for objectively estimating forecast uncertainty, which

Keywords. Tropical cyclone; landfall; North Indian Ocean; error. 
is used in deciding the timing and extent of warnings and watches, especially for critical regions; (iv) providing feedback on the relative accuracy of available forecast techniques, perhaps including stratification into different synoptic, latitudinal, or seasonal types (e.g., Neumann and Pelissier 1981); and (v) providing feedback to external organisations, such as the global and regional modelling centres for comparison of their performance in the region with the official forecast.

Improved short range (1-3 days) landfall forecasts lead to fewer unnecessary warnings and evacuations. Additionally, a better landfall forecast will yield improved forecasts of other metrics such as wind speed, storm surge, and precipitation in terms of their spatial distribution. However, the better landfall forecast may not improve the intensity of TC and associated adverse weather phenomena as mentioned above.

India Meteorological Department (IMD), as one of the six Regional Specialised Meteorological Centres (RSMCs), is responsible for TC monitoring and prediction over the NIO. A cyclonic disturbance is considered as a TC over the NIO, when the associated maximum sustained surface wind (MSW) is 34 knots or more as per the classification adopted by IMD. It corresponds to the definition of tropical storms over other ocean basins like Pacific and Atlantic Oceans. Detailed classification of TCs into cyclonic storm (CS), severe cyclonic storm (SCS), very severe cyclonic storm (VSCS), and super cyclonic storm (SuCS) are given in cyclone manual published by IMD $(2003,2013)$.

IMD introduced the objective TC landfall forecast valid for next $24 \mathrm{hrs}$ over the NIO in 2003 . It further extended the validity period up to $72 \mathrm{hrs}$ in 2009. It may be mentioned that the RSMC, Tokyo introduced 24-hr objective forecast in 1982, 48-hr forecast in 1988, 72-hr forecast in 1997, and 96 and 120-hr forecast in 2009 for northwest Pacific Ocean (RSMC, Tokyo 2011). Similarly, National Hurricane Centre (NHC) and RSMC, Miami, USA introduced 24-hr objective forecast in 1954, 48-hr forecast in 1961, 72-hr forecast in 1972, and 96 and 120-hr forecast in 2001 for Atlantic Ocean (NHC 2012). Prior to 2003, the TC forecasts issued by IMD for the NIO were subjective and textual in form without mentioning expected location of the TC in 12 and 24-hr forecast period in objective manner.

In order to compare forecasts made in extremely variable conditions and evaluate their quality by including these forecasts' degree of difficulty (in particular with the aim of detecting forecasts' trends with time), there are several possible options. The first, being the measurement of landfall forecast error. Most of the TC forecasting centres including NHC, USA, and RSMC, Tokyo verify their TC landfall forecasts regularly on an yearly basis. RSMC, New Delhi introduced the objective TC forecast verification in 2009 (RSMS, New Delhi, 2010). The TC landfall forecast errors can be analysed from several perspectives. The most common is the absolute position error and time error. The landfall point error is the great circle distance between a TC's forecast landfall point and the observed landfall point irrespective of the time of landfall. Similarly, the landfall time forecast error is the difference of the time of forecast landfall and time of observed landfall.

Here, an attempt is made to evaluate the TC landfall forecast issued by IMD during 2003-2013 (11 years) based on the calculation of landfall point and time forecast errors.

The forecaster's awareness of the above-mentioned forecast error measure represents an important factor in the overall decision process relative to the formulation of TC warnings and advisories (Simpson 1971). Hence, apart from the utilities as mentioned in the first paragraph, this study can be utilized to interpret the landfall forecast properly and decide effective cyclone management response actions by the disaster managers. Further, though the TC landfall forecasts have been steadily improving for several decades, some uncertainty still remains. A part of this uncertainty is due to an inherent predictability bound that future improvements in numerical models and in forecasting techniques will not be able to overcome (Fraedrich and Leslie 1989; Plu 2011). End users of TC forecasts, such as risk managers and public agencies, need both reliable track forecasts and an estimation of the forecast uncertainty, especially with respect to landfall point and time. To determine these uncertainties, it is essential to know the forecast errors in the past years.

\section{Data and methodology}

The data sample for this purpose is composed of all TCs with different intensities (CS and above) over the NIO (north of equator and between longitude $45^{\circ}$ and $100^{\circ} \mathrm{E}$ ), over the period of 11 years (2003-2013). The landfall forecast has been issued by RSMC, New Delhi from deep depression stage onwards since 2009 for $12,24,36,48,60$, and 72-hr forecast periods. It has been extended to $120 \mathrm{hrs}$ in 2013. It has been issued during CS stage onwards during 2003-2008 and for 12 and 24-hr forecast periods only. The TC landfall forecast issued 4 times a day at the interval of six hours, i.e., based on 00, 06, 12 and 18 UTC observations has been verified during 2003-2013. The forecasts are issued about three hours after the above-mentioned observation time. As data are not 
sufficient to verify for 96 and $120 \mathrm{hrs}$, the verification of landfall forecasts has been restricted up to $72 \mathrm{hrs}$ for the period of 2009-2013 and up to $24 \mathrm{hrs}$ for the period of 2003-2008. The RSMC forecast landfall results from a manually analyzed forecasting process, which relies on output from several numerical weather prediction (NWP) models (RSMC, New Delhi, 2013) including IMD Global Forecast System (GFS), India's National Centre for Medium Range Weather Forecast (NCMRWF), European Centre for Medium Range Weather Forecast (ECMWF), the UK Meteorological Office, Japan Meteorological Agency (JMA), ARP-Meteo-France, National Centre for Environmental Prediction (NCEP) GFS and some ensemble means like multi-model ensemble (MME) and single model ensemble prediction system (EPS). Also the regional models like meso-scale model-MM5, Weather Research Forecast (WRF) Model, Quasi-Lagrangian Model (QLM), Hurricane WRF (HWRF) Model are utilized for TC track and landfall prediction. These models provide forecast guidance up to $72 \mathrm{hrs}$. Most of the above-mentioned models are run based on 0000 and 1200 UTC initial conditions. While QLM was available in IMD since the beginning of 2000, other regional models are new additions in IMD's NWP system. HWRF model is the latest addition in 2013 only. Consensus forecasts that gather all or part of the numerical forecast tracks and use synoptic and statistical guidance are utilised to issue official forecast.

A total of 31 TCs during 2003-2013 (figure 1a, table 1) has been considered in the study including 24 over the Bay of Bengal (BOB) and 7 over the Arabian Sea (AS) making 33 landfalls, as TC, PHET during 31 May-7 June 2010 had two landfalls, one over Oman and the other over Pakistan and TC, GONU during 1-7 June 2007 had two

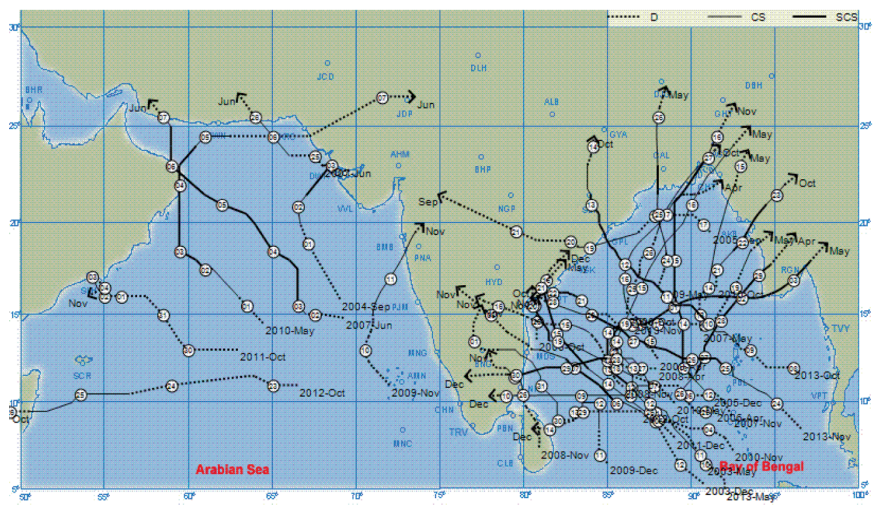

(a) landfalls, one over Oman and the other over Iran. Detailed characteristics of the TCs considered in the study are given in table 1 . The landfall forecasts issued for $12,24,36,48,60$, and $72 \mathrm{hrs}$ before the actual time of landfall of a given TC have been verified against the IMD's best track based actual point and time of landfall. The lead time of such forecast decreases if the life period of the TC is less or it dissipates rapidly.

In this study, the TC is said to have made landfall, when the centre of the TC lies over the land, though destructive effects may occur several hours before and after the landfall time and extend several hundred kilometers from the landfall point in the coast line. Observed landfall positions are accurate to within $\pm 30 \mathrm{~km}$ as estimated by Mohapatra et al. (2012b). Accuracy of observed landfall times is estimated to be $\pm 0.5 \mathrm{hr}$, as during the period of study, hourly satellite, radar and coastal synoptic observations were used by IMD to monitor the location of TCs. An example of calculation of the landfall forecast error based on forecast track and the observed best track is shown in figure 1(b). The landfall point forecast error (LPE) is measured by the distance between the RSMC forecast landfall point and the actual landfall point according to RSMC best-track estimates. Similarly, the landfall time forecast error (LTE) is measured by the difference in the RSMC forecast landfall time and the actual landfall time according to RSMC besttrack estimates. As the forecast landfall point and time may not be the positions defined at 00, 06, 12, and 18 UTC in forecast track, the forecast landfall point and time have been determined by applying the linear interpolation technique to the forecast location before landfall and after landfall.

The performance of available NWP model guidance with respect to TC landfall forecast has also been verified and the model errors have been

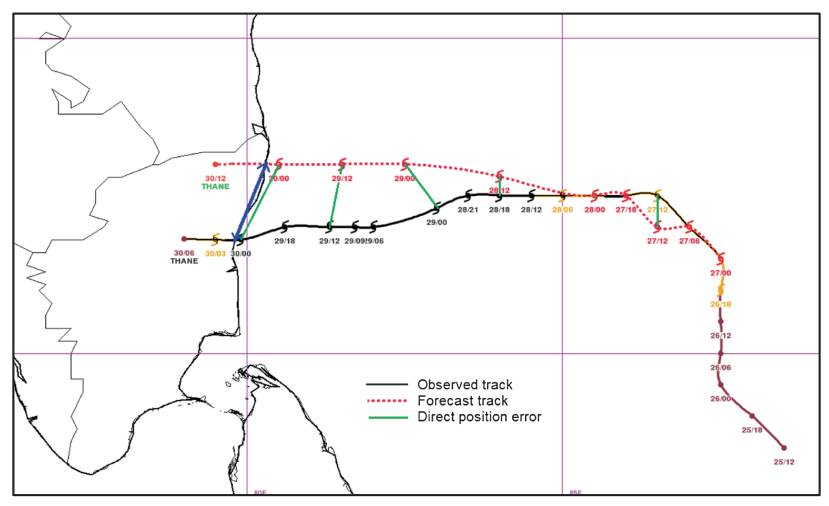

(b)

Figure 1. (a) Tracks of tropical cyclones (TCs) during 2003-2013 under consideration in study and (b) an example of calculation of landfall point forecast error based on 0000 UTC of 27 December, 2011 in case of cyclone, Thane. Blue line indicates the landfall point forecast error (distance between forecast landfall point and observed landfall point). 
Table 1. Details of the tropical cyclones (TCs) under consideration.

\begin{tabular}{|c|c|c|c|c|c|c|c|}
\hline Sl. no. & Year & Life period & $\begin{array}{l}\text { Maximum } \\
\text { intensity }\end{array}$ & $\begin{array}{l}\text { Basin of } \\
\text { formation }\end{array}$ & $\begin{array}{l}\text { Season of } \\
\text { formation }\end{array}$ & $\begin{array}{l}\text { Type of } \\
\text { track of TC }\end{array}$ & $\begin{array}{c}\text { Region of } \\
\text { landfall }\end{array}$ \\
\hline 1 & 2003 & 10-19 May & $\mathrm{D}$ & $\mathrm{BOB}$ & Pre-M & $\mathrm{R}$ & Myanmar \\
\hline 2 & 2003 & 11-16 Dec & SCS & $\mathrm{BOB}$ & Post-M & $\mathrm{R}$ & $\mathrm{AP}$ \\
\hline 3 & 2004 & 30 Sept-3 Oct & SCS & AS & Post-M & $\mathrm{R}$ & Gujarat \\
\hline 4 & 2005 & 17-21 Sept & CS & $\mathrm{BOB}$ & $\mathrm{M}$ & $\mathrm{R}$ & $\mathrm{AP}$ \\
\hline 5 & 2005 & 6-10 Dec & CS & $\mathrm{BOB}$ & Post-M & $\mathrm{S} / \mathrm{C}$ & $\mathrm{TN}$ \\
\hline 6 & 2006 & 25-29 April & SCS & $\mathrm{BOB}$ & Pre-M & $\mathrm{R}$ & Myanmar \\
\hline 7 & 2006 & 29-30 Oct & CS & $\mathrm{BOB}$ & Post-M & $\mathrm{S} / \mathrm{C}$ & $\mathrm{AP}$ \\
\hline 8 & 2007 & 13-15 May & CS & $\mathrm{BOB}$ & Pre-M & $\mathrm{S} / \mathrm{C}$ & Bangladesh \\
\hline 9 & 2007 & 1-7 June & SCS, CS & AS & M & $\mathrm{S} / \mathrm{C}$ & Oman, Iran \\
\hline 10 & 2007 & 25-26 June & CS & AS & M & $\mathrm{S} / \mathrm{C}$ & Pakistan \\
\hline 11 & 2007 & 11-16 Nov & SCS & $\mathrm{BOB}$ & Post-M & $\mathrm{R}$ & Bangladesh \\
\hline 12 & 2008 & 27 April -3 May & SCS & BOB & Pre-M & $\mathrm{R}$ & Myanmar \\
\hline 13 & 2008 & 25-27 Oct & CS & $\mathrm{BOB}$ & Post-M & $\mathrm{S} / \mathrm{C}$ & Bangladesh \\
\hline 14 & 2008 & $13-16 \mathrm{Nov}$ & $\mathrm{D}$ & $\mathrm{BOB}$ & Post-M & $\mathrm{S} / \mathrm{C}$ & $\mathrm{AP}$ \\
\hline 15 & 2008 & 25-27 Nov & CS & $\mathrm{BOB}$ & Post-M & $\mathrm{S} / \mathrm{C}$ & $\mathrm{TN}$ \\
\hline 16 & 2009 & 14-17 April & $\mathrm{D}$ & $\mathrm{BOB}$ & Pre-M & $\mathrm{R}$ & Bangladesh \\
\hline 17 & 2009 & 23-26 May & SCS & $\mathrm{BOB}$ & Pre-M & $\mathrm{S} / \mathrm{C}$ & WB \\
\hline 18 & 2009 & $9-12 \mathrm{Nov}$ & CS & AS & Post-M & $\mathrm{R}$ & Maharashtra \\
\hline 19 & 2009 & 10-15 Dec & $\mathrm{D}$ & $\mathrm{BOB}$ & Post-M & $\mathrm{R}$ & Sri Lanka \\
\hline 20 & 2010 & 17-21 May & SCS & $\mathrm{BOB}$ & Pre-M & $\mathrm{R}$ & $\mathrm{AP}$ \\
\hline 21 & 2010 & 31 May 7 June & SCS, D & AS & Pre-M & $\mathrm{R}$ & Oman, Pakistan \\
\hline 22 & 2010 & 20-23 Oct & SCS & $\mathrm{BOB}$ & Post-M & $\mathrm{S} / \mathrm{C}$ & Myanmar \\
\hline 23 & 2010 & 04-08 Nov & $\mathrm{CS}$ & $\mathrm{BOB}$ & Post-M & $\mathrm{S} / \mathrm{C}$ & $\mathrm{TN}$ \\
\hline 24 & 2011 & 29 Oct-4 Nov & CS & AS & Post-M & $\mathrm{R}$ & Oman \\
\hline 25 & 2011 & 25-31 Dec & SCS & $\mathrm{BOB}$ & Post-M & $\mathrm{S} / \mathrm{C}$ & $\mathrm{TN}$ \\
\hline 26 & 2012 & 28 Oct-1 Nov & CS & $\mathrm{BOB}$ & Post-M & $\mathrm{R}$ & $\mathrm{TN}$ \\
\hline 27 & 2012 & $22-26$ Oct & CS & AS & Post-M & $\mathrm{S} / \mathrm{C}$ & Somalia \\
\hline 28 & 2013 & 10-16 May & CS & $\mathrm{BOB}$ & Pre-M & $\mathrm{R}$ & Bangladesh \\
\hline 29 & 2013 & 8-14 Oct & SCS & $\mathrm{BOB}$ & Post-M & $\mathrm{S} / \mathrm{C}$ & Odisha \\
\hline 30 & 2013 & 19-22 Nov & CS & $\mathrm{BOB}$ & Post-M & $\mathrm{S} / \mathrm{C}$ & $\mathrm{AP}$ \\
\hline 31 & 2013 & $23-28 \mathrm{Nov}$ & $\mathrm{D}$ & BOB & Post-M & $\mathrm{S} / \mathrm{C}$ & $\mathrm{AP}$ \\
\hline
\end{tabular}

Note. D: depression, CS: Cyclonic storm, SCS: Severe cyclonic storm or higher intensity, BOB: Bay of Bengal, AS: Arabian Sea, Pre-M: Pre-monsoon, Post-M: Post-monsoon, M: Monsoon, R: Recurving/looping, S/C: straight moving/ climatological, AP: Andhra Pradesh, TN: Tamil Nadu.

compared with the IMD's operational forecast errors. As the NWP models were made available in recent years due to installation of High Power Computing System (HPCS), the NWP models' performance has been evaluated for the period of 2009-2013 only.

The accuracy of TC landfall forecast has been further analysed with respect to basin of formation (BOB, AS, and NIO as a whole), coast of landfall, season of formation (pre-monsoon (March-May) and post-monsoon (October-December) seasons), intensity of TCs (depression/deep depression (D/DD), CS and SCS or higher intensities) at the time of initiation of forecast and type of track of TCs (climatological/straight moving and recurving/looping type). The dataset includes $6 \mathrm{D} / \mathrm{DD}$, 15 CS, and 12 SCS or higher intensity at landfall (table 2). Forecast accuracy depends upon accuracy of initial $\mathrm{TC}$ vortex position and intensity at the time of initialisation of models and hence, the time of issue of official forecast (Mohanty et al. 2010; Osuri et al. 2011). Hence, the TC landfall forecast errors with respect to three different categories of intensity of TCs at the time of initialisation of forecast have been calculated and analysed. The TCs show bi-modal behaviour in their genesis with primary maxima in post-monsoon season and secondary maxima in pre-monsoon season. The performance of TC landfall forecast has been analysed during these two seasons separately, as their track, genesis, and intensification characteristics are different in these two different seasons. There have been three landfalling TCs during monsoon months (two in June and one in September). 
Since the systems in the month of June during onset phase of monsoon have pre-monsoon characteristics, they have been considered as the TCs in pre-monsoon season for analysis purpose. Similarly, the TC in September has been considered in the category of the post-monsoon season, as it occurred during withdrawal phase of monsoon. As such, there are 13 and 20 landfalls during premonsoon and post-monsoon seasons respectively. There are 24 and 9 landfalls respectively for the TCs over the BOB and AS (table 2).

The results are analysed and presented in section 3. The limitations and future scope are presented in section 4 . The broad conclusions are presented in section 5 .

\section{Results and discussion}

The LPE and LTE have been analysed with respect to basin of formation (BOB, AS, NIO as a whole) of TCs, coast of landfall, type of track, intensity of
TCs (CS and SCS or higher intensities) at the time of landfall and season of formation (pre-monsoon and post-monsoon) of TCs and the results are presented and discussed in subsections 3.1-3.6. The interannual variation in the LPE and LTE are analysed and discussed in subsection 3.7.

\subsection{Average landfall forecast error over the NIO}

The statistics of LPE and LTE for the TCs over the NIO are presented in figure 2( $\mathrm{a}$ and $\mathrm{b}$ ) respectively. There are 107 cases of landfall forecasts for different forecast times ranging from 12 to $72 \mathrm{hrs}$ (table 2). It is found that the average LPE during 2003-2013 is about 104, 95 and $124 \mathrm{~km}$, respectively for 24, 48, and 72-hr forecasts. Comparison of LPE and track forecast errors indicate that the LPE is significantly less than the track forecast error (Mohapatra et al. 2013a). It may be due to the fact that the LPE does not take into consideration the time error involved in the forecast.

Table 2. Statistics of official landfall forecasts of TCs verified during 2003-2013.

\begin{tabular}{|c|c|c|c|c|c|c|c|c|c|c|}
\hline \multirow{2}{*}{$\begin{array}{l}\text { Forecast } \\
\text { period } \\
(\mathrm{hrs})\end{array}$} & \multicolumn{3}{|c|}{ Basin of formation } & \multicolumn{2}{|c|}{ Season of formation } & \multicolumn{2}{|c|}{ Type of track } & \multicolumn{3}{|c|}{$\begin{array}{l}\text { Intensity of TCs at the } \\
\text { time of issue of forecast }\end{array}$} \\
\hline & $\begin{array}{l}\mathrm{BOB} \\
(25)\end{array}$ & $\begin{array}{l}\mathrm{AS} \\
(8)\end{array}$ & $\begin{array}{l}\text { NIO } \\
(33)\end{array}$ & $\begin{array}{c}\text { Pre-M } \\
(14)\end{array}$ & $\begin{array}{c}\text { Post-M } \\
(19)\end{array}$ & $\begin{array}{l}\mathrm{C} / \mathrm{S} \\
(17)\end{array}$ & $\begin{array}{c}\mathrm{R} \\
(16)\end{array}$ & $\begin{array}{c}\mathrm{D} / \mathrm{DD} \\
(07)\end{array}$ & $\begin{array}{l}\text { CS } \\
(13)\end{array}$ & $\begin{array}{l}\text { SCS } \\
(13)\end{array}$ \\
\hline 12 & 25 & 8 & 33 & 14 & 19 & 17 & 16 & 6 & 13 & 13 \\
\hline 24 & 23 & 6 & 29 & 11 & 18 & 15 & 14 & 6 & 09 & 13 \\
\hline 36 & 12 & 4 & 16 & 5 & 11 & 8 & 08 & 8 & 4 & 7 \\
\hline 48 & 11 & 2 & 13 & 5 & 8 & 6 & 07 & 2 & 7 & 3 \\
\hline 60 & 8 & 1 & 9 & 3 & 6 & 5 & 04 & 3 & 3 & 3 \\
\hline 72 & 6 & 1 & 7 & 3 & 4 & 4 & 03 & 2 & 4 & 1 \\
\hline Total & 85 & 22 & 107 & 41 & 66 & 55 & 52 & 27 & 40 & 40 \\
\hline
\end{tabular}

Note. Figures given within parentheses in the first row indicate the number of landfalls of TCs. C/S: Climatological/ straight moving, R: Recurving, Pre-M: Pre-monsoon, Post-M: Post-monsoon, D: Depression, CS: Cyclonic storm, SCS: Severe cyclonic storm or higher intensity, BOB: Bay of Bengal, AS: Arabian Sea, NIO: North Indian Ocean.
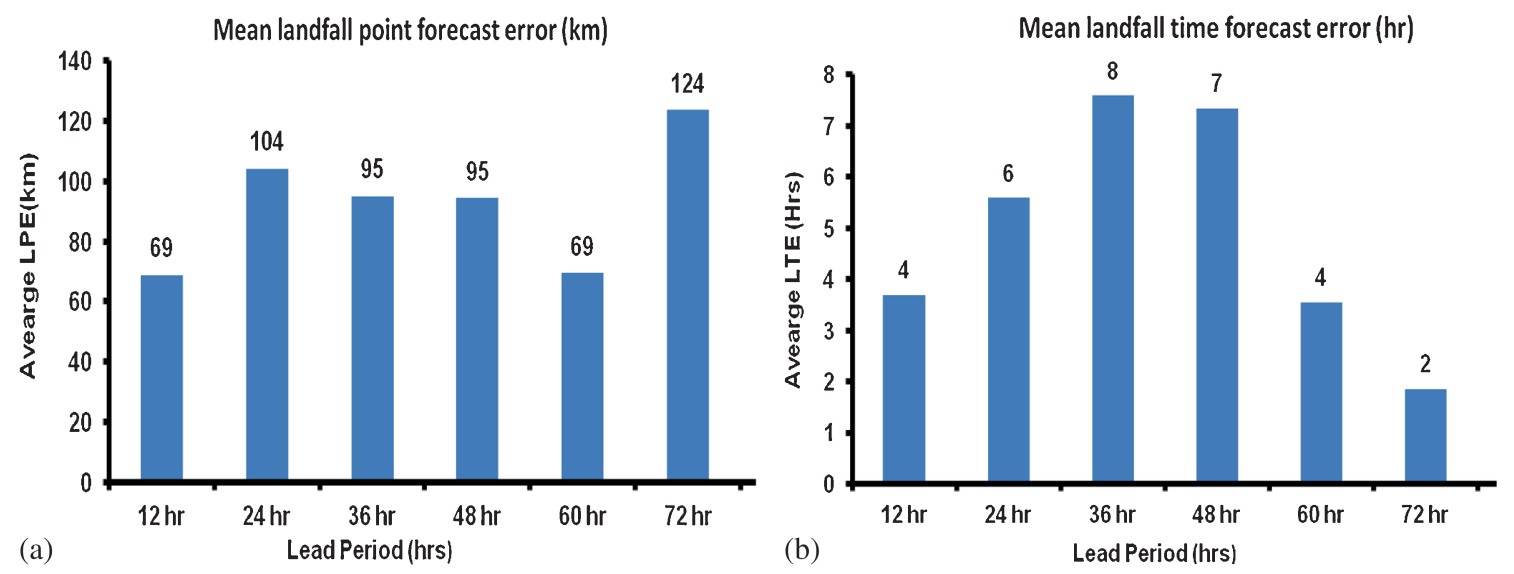

Figure 2. (a) Average landfall point forecast error (LPE) and (b) average landfall time forecast error (LTE) for TCs over the NIO during 2003-2013. 
Considering the period of 2009-2013, there has been significant improvement in monitoring and prediction of TCs over the NIO due to modernization programme of IMD (table 3 ). Comparing the LPE for the TCs over the NIO during 2003-2008 and 2009-2013, it is found that the LPE has been significantly less during recent years, as 12 and 24hr LPEs during 2009-2013 are 47.5 and $66.5 \mathrm{~km}$ against 91.6 and $157.5 \mathrm{~km}$, respectively during 2003-2008 (table 3). Considering the LTE, there has also been significant improvement in recent years over the NIO, as the LTE is about 2.4 and $4.1 \mathrm{hrs}$ for 12 and 24-hr forecasts respectively during 2009-2013 against 5.0 and 7.8 hrs during 2003-2008 (table 3). The LTEs for 48 and 72-hr forecasts are 7.3 and $1.9 \mathrm{hrs}$, respectively during 2009-2013 (figure 2b). The difference in both LPEs and LTEs during 2003-2008 and 2009-2013 is significant at $95 \%$ confidence level according to one tailed Students $t$ test. Significant decrease in LPE and LTE in recent years may be due to improvement in track forecast error (Mohapatra et al. 2013a), which has improved at the rate of
$7 \mathrm{~km} /$ year for 24-hr forecast. The overall improvement in TC forecasting by IMD in recent years may be attributed to modernization programme of IMD, especially with respect to cyclone warning system, which includes upgradation of land-based observations, high power computing, and improved global and regional NWP system through national and international collaboration and digitized decision support system for TC monitoring and prediction. All these activities of modernization commenced from 2009. Details of the activities leading to improvement in TC forecasting by IMD have been discussed by Mohapatra et al. (2013b). As a result of IMD's modernization programme, the surface observational network has been enhanced from about 550 surface observatories in India to 1175 observatories (due to 675 Automated Weather Stations). It has led to decrease in landfall point estimation error from $50 \mathrm{~km}$ to about $30 \mathrm{~km}$ (Mohapatra et al. 2012b). Similarly, the introduction of 11 GPS Radio Sonde/Radio Wind (RS/RW) stations have resulted in quality improvement of upper air data and hence the NWP

Table 3. Landfall forecast errors of TCs over the NIO during 2003-2008 and 2009-2013.

\begin{tabular}{|c|c|c|c|c|c|c|}
\hline \multirow[b]{2}{*}{ TCs } & \multirow{2}{*}{$\begin{array}{l}\text { Lead } \\
\text { period }\end{array}$} & \multirow{2}{*}{$\begin{array}{c}\text { No. of forecasts } \\
(2003-2008 / 2009-2013)\end{array}$} & \multicolumn{2}{|c|}{ LPE $(\mathrm{km})$} & \multicolumn{2}{|c|}{ LTE (hr) } \\
\hline & & & $2003-2008$ & $2009-2013$ & $2003-2008$ & $2009-2013$ \\
\hline \multirow{2}{*}{ All } & $\int 12$ & $16 / 17$ & 91.6 & 47.5 & 5.0 & 2.4 \\
\hline & 24 & $12 / 17$ & 157.5 & 66.5 & 7.8 & 4.1 \\
\hline \multicolumn{7}{|c|}{ Intensity of $\mathrm{TC}$ at the time of issue of forecasts } \\
\hline \multirow{2}{*}{ D/DD } & $\int 12$ & $04 / 02$ & 78.5 & 93.0 & 4.8 & 2.0 \\
\hline & 24 & $03 / 03$ & 150.0 & 63.3 & 14.3 & 5.3 \\
\hline \multirow{2}{*}{ CS } & $\int 12$ & $05 / 09$ & 88.6 & 66.5 & 5.0 & 3.4 \\
\hline & 24 & $03 / 06$ & 109.0 & 70.0 & 8.0 & 3.8 \\
\hline \multirow{2}{*}{ SCS } & $\int 12$ & $07 / 06$ & 102.3 & 29.7 & 4.4 & 2.2 \\
\hline & $\{24$ & $05 / 08$ & 199.2 & 64.7 & 2.5 & $4 \cdot 4$ \\
\hline \multicolumn{7}{|c|}{ Region of formation } \\
\hline \multirow{2}{*}{$\mathrm{AS}$} & $\int 12$ & $03 / 05$ & 75.3 & 76.7 & 8.3 & 2.5 \\
\hline & 24 & $01 / 05$ & 25.0 & 127.0 & 2.0 & 4.3 \\
\hline \multirow{2}{*}{$\mathrm{BOB}$} & $\int 12$ & $13 / 12$ & 95.3 & 35.4 & 4.3 & 2.4 \\
\hline & 24 & $11 / 12$ & 169.5 & 41.3 & 8.3 & 4.0 \\
\hline \multicolumn{7}{|c|}{ Season of formation } \\
\hline \multirow{2}{*}{ Pre-M } & $\int 12$ & 08/06 & 98.4 & 32.0 & 6.2 & 2.9 \\
\hline & $\{24$ & $05 / 06$ & 169.2 & 87.8 & 5.5 & 5.3 \\
\hline \multirow{2}{*}{ Post-M } & $\int 12$ & $08 / 11$ & 84.7 & 56.0 & 3.9 & 2.2 \\
\hline & 24 & $07 / 11$ & 149.1 & 54.9 & 9.4 & 3.4 \\
\hline \multicolumn{7}{|c|}{ Type of track } \\
\hline \multirow{2}{*}{$\mathrm{C} / \mathrm{S}$} & $\int 12$ & $09 / 08$ & 59.8 & 31.0 & 6.1 & 1.9 \\
\hline & $\{24$ & 07/08 & 102.9 & 33.4 & 9.7 & 3.1 \\
\hline \multirow{2}{*}{$\mathrm{R}$} & $\int 12$ & 07/09 & 132.4 & 62.2 & 3.7 & 2.9 \\
\hline & $\{24$ & 05/09 & 234.0 & 96.0 & 5.0 & 4.9 \\
\hline
\end{tabular}

Note. LPE: Landfall point forecast error, LTE: Landfall time forecast error, C/S: Climatological/straight moving, R: Recurving, Pre-M: Pre-monsoon, Post-M: Post-monsoon, D/DD: Depression/deep depression, CS: Cyclonic storm, SCS: Severe cyclonic storm or higher intensity, BOB: Bay of Bengal, AS: Arabian Sea. The LPEs and LTEs during 2009-2013, which significantly differ from that during 2003-2008 at $95 \%$ and $90 \%$ confidence level are shown in bold and italic, respectively. 
model performance. Due to installation of Doppler Weather Radar (DWR) along the coast, the detection of TC near the coast has been more accurate. Further, the assimilation of radar data in NWP models also resulted in forecast improvement. At the same time, there has been improvement in ocean-based observations due to deployment of meteorological buoys over the NIO by National Institute of Ocean Technology (NIOT), space-based observations due to commissioning of OceanSatII satellite by Indian Space Research Organisation (ISRO), and availability of various products by the global initiatives. Due to various national and international collaborations like that with NCEP, USA, JMA, UKMO, National Centre for Medium Range Weather Forecast (NCMRWF), India, Indian Institute of Technology (IIT), Delhi and Indian Air Force (IAF), etc., the number of global and regional models products available to TC forecasters has increased significantly. As a result, IMD has also developed MME and EPS products for TC forecasting. Installation of decision support system to analyse, compare and draw inference based on available observation and model products also helped forecasters to minimize the subjectivity and improve the TC forecasting accuracy.

To find out the contribution of NWP models' guidance to the official forecast of IMD, the landfall forecast errors of various global and regional models are calculated and analysed. The LPE and LTE of these models for the landfalling TCs over the NIO during 2009-2013 along with the official LPE and LTE of IMD are presented in figure 3(a and b), respectively. It is observed that there is large variation in the performance of the models. However, the performance of ECMWF model is better and more consistent than other deterministic models. The performance of MME, which is operationally followed mostly by IMD is also better as the LPE varies from $56 \mathrm{~km}$ for 12-hr lead period to $89 \mathrm{~km}$ for 72 -hr lead period. Comparing the errors of MME with official forecasts, the official forecast error is less than that of MME up to 24-hr forecast and almost same as that of MME for 36 and 48-hr forecasts. The official error is also similar to that of ECMWF. It indicates that there is value addition to NWP model guidance up to 24-hr forecast based on synoptic and climatological analysis and the forecast beyond $24 \mathrm{hrs}$ is mainly based on MME and ECMWF model guidance. Similar is the situation considering the LTEs (figure 3b).

\subsection{Landfall forecast error with respect to basin of formation of TCs}

The statistics of LPE and LTE are shown in figure 4 for the TCs over BOB and AS. There are
24 and nine landfalls from the TCs over the BOB and AS respectively during 2003-2013. There are 85 and 22 cases of landfall forecasts for different forecast lengths (table 2) for TCs over the BOB and $\mathrm{AS}$ respectively. It is found that the LPE is less over the BOB than over the AS for all lead periods of forecast up to $60 \mathrm{hrs}$. However, the difference in LPEs is statistically significant at $95 \%$ confidence level for 36-hr forecast only. Similarly, the LTE is also less over the BOB for different lead periods of forecast up to $48 \mathrm{hrs}$. The results are similar to those observed in case of the track forecast errors (Mohapatra et al. 2013a). The higher accuracy over the BOB may be attributed to the fact that the open sea area, which is a data sparse region is relatively less in case of $\mathrm{BOB}$ than in AS. While there is a dense observatory network along the coast surrounding the BOB due to dense coastal observatories and cyclone detection radars, the coastal area surrounding AS does not have such a network. It leads to more accurate determination of location and intensity over BOB than in AS (Mohapatra et al. 2012b). The higher initial error in location and intensity estimation over the AS leads to higher track forecast error (Mohanty et al. 2010; Osuri et al. 2011) and hence landfall forecast error. Another reason for higher LPE and LTE over the AS may be due to the fact that the percentage of recurving/looping TCs is higher over the AS than over the BOB. While five out of nine (55\%) tracks of landfalling TCs over the AS are of the recurving/looping type, it is 11 out of $24(46 \%)$ over the BOB, which are of the recurving/looping type. As it will be shown in the next subsection, the LPE and LTE are higher for the recurving/looping type of TCs than that for climatological/straight moving TCs.

Comparing the LPEs during 2003-2008 and 2009-2013, there is significant improvement in forecast with reduction of LPE for both 12 and 24-hr forecasts during 2009-2013 over the BOB at $95 \%$ confidence level. Also there is significant decrease in LTE during 2009-2013 over the BOB at 95\% confidence level for $24-\mathrm{hr}$ forecasts and at $90 \%$ level for 12-hr forecast.

\subsection{Landfall forecast error with respect to nature of the track of TCs}

As it is evident from figure 1, the TCs follow different track characteristics. It is a well established fact that the predictability is less in case of recurving and looping TCs and more in case of straight moving TCs (Mohapatra et al. 2012c, 2013a). Neumann and Pelissier (1981) have demonstrated it over the Atlantic Ocean based on official forecast of NHC. To find out the impact of nature of track 
Landfall point forecast errors $(\mathbf{k m})$

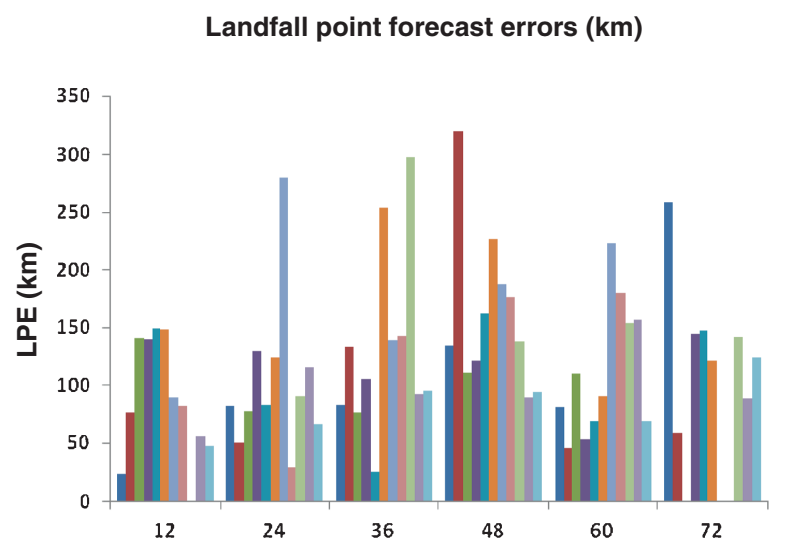

(a)

Lead Period (Hrs)

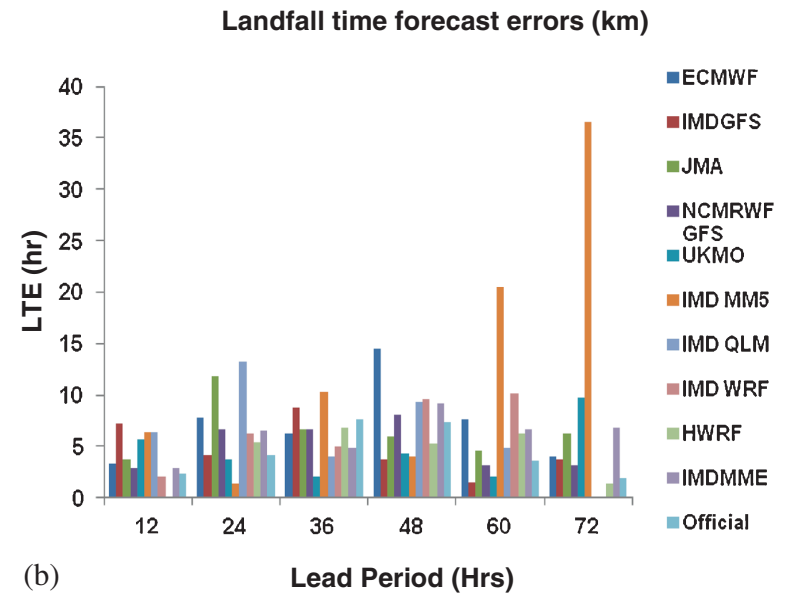

Figure 3. (a) Landfall point forecast errors (LPEs) and (b) landfall time forecast errors (LTEs) of various NWP models used by IMD for TC forecasting over NIO during 2009-2013.

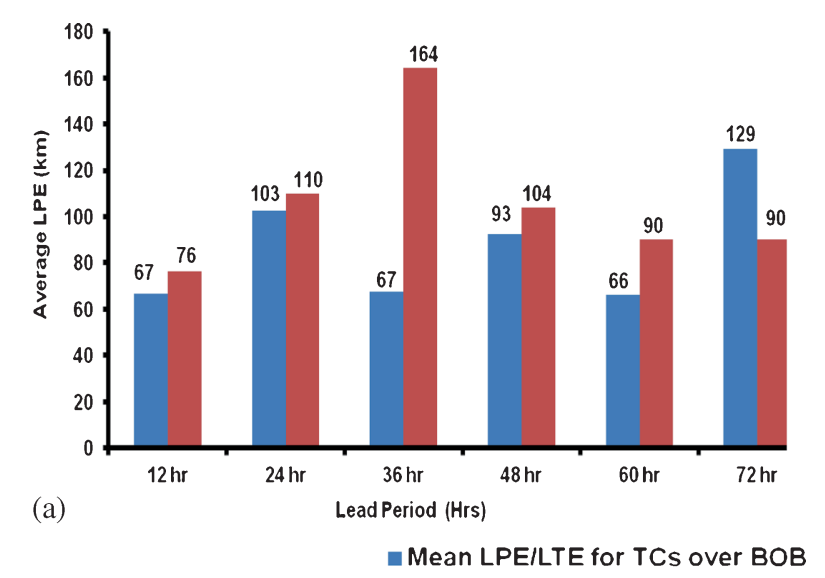

Figure 4. (a) Average landfall point forecast error (LPE) and the BOB and AS.

on TC landfall forecast, the TCs over the NIO have been further categorized as climatological/straight moving and recurving TCs and the corresponding landfall forecast error has been analysed and discussed. There are 17 and 16 such TCs of different intensities in these two categories respectively. There are 55 and 52 cases of landfall forecast for different forecast lengths (table 2) for climatolog$\mathrm{ical} /$ straight moving and recurving/looping TCs, respectively.

The statistics of LPE and LTE are shown in figure 5 for the climatological/straight moving and recurving/looping TCs. It is found that the LPE is higher in case of recurving TCs, being about 145 , 104, and $154 \mathrm{~km}$ for 24, 48, and 72-hr forecasts, respectively. It is about 66,82 , and $101 \mathrm{~km}$ respectively for 24,48 , and 72 -hr forecasts in case of climatological/straight moving TCs. However, the difference in LPEs is significant at $95 \%$ confidence level for 12, 24, and 36-hr forecasts. Considering the LTE (figure 5b) for the above two categories

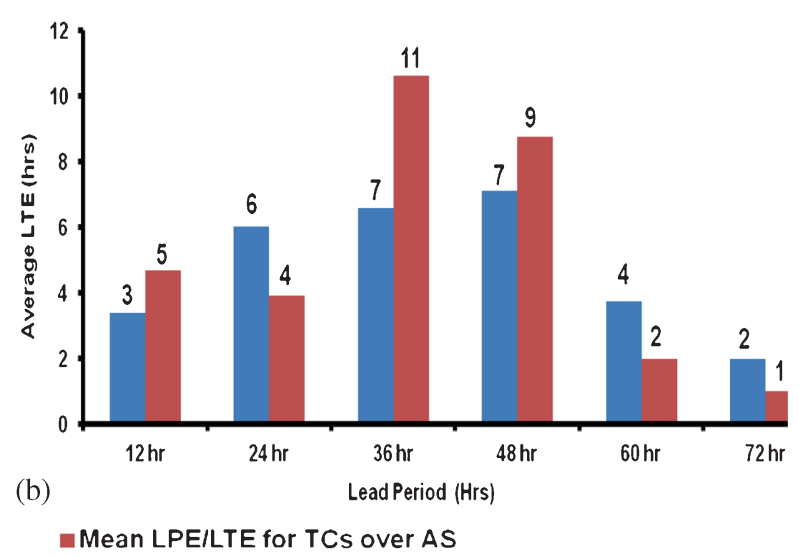

(b) average landfall time forecast error (LTE) for TCs over of TCs, the LTE is also higher in case of recurving TCs for 36 to 72 -hr forecasts. The difference in LTEs is significant at $95 \%$ confidence level for 36 and 48-hr forecasts.

Comparing the LPEs and LTEs during 20032008 and 2009-2013, there has been significant improvement in landfall forecasts for recurving TCs in recent years (table 3 ). There is significant reduction of LPE for both 12 and 24-hr forecasts during 2009-2013 in case of both climatological/straight moving TCs and recurving TCs. Also there is significant decrease in LTE during 2009-2013 in case of climatological/straight moving TCs at $95 \%$ confidence level for 12 and 24-hr forecasts. Straight moving TCs usually cross the coast perpendicularly or obliquely. The recurving TCs move parallel to the coast and at last cross the coast obliquely. According to Powell and Aberson (2001), for TCs landfalling over United States during 1976-2000, within $55 \mathrm{hr}$ of predicted landfall, track forecasts parallel to the coastline have larger 

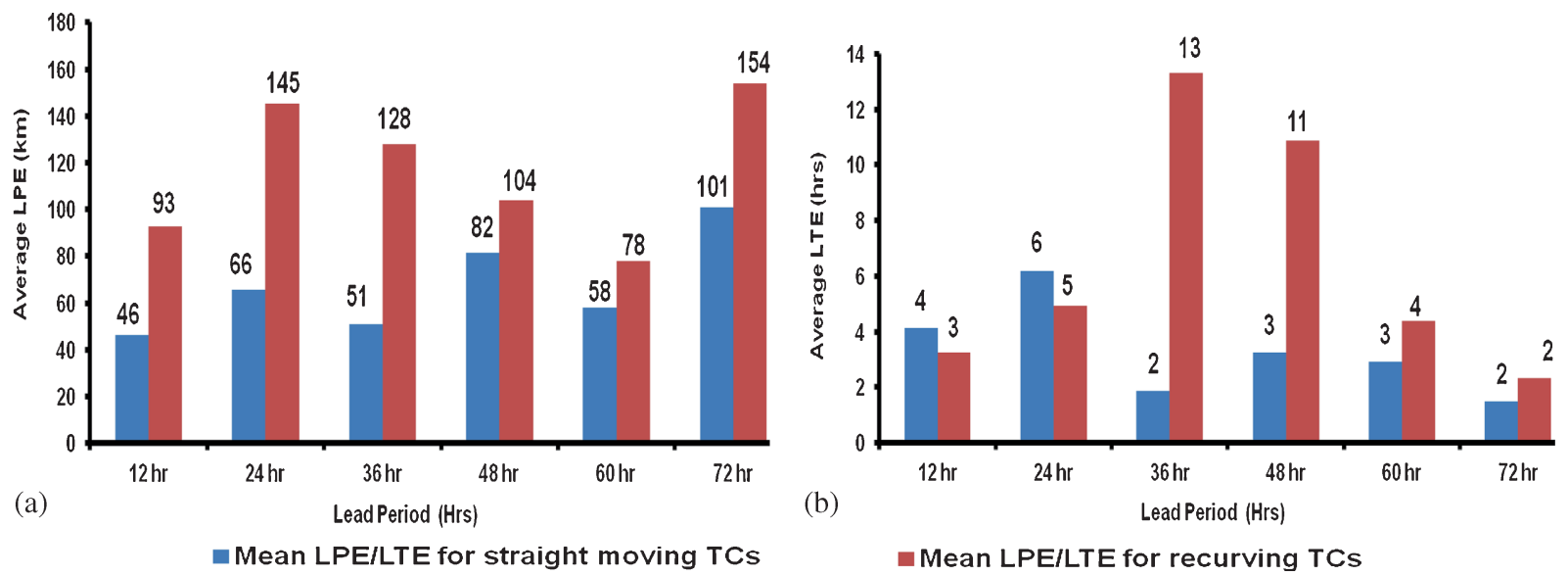

Figure 5. (a) Average landfall point forecast error (LPE) and (b) average landfall time forecast error (LTE) for straight moving and recurving TCs over the NIO based on data of 2003-2013.

time errors, larger early biases, and larger standard deviations in the forecast position and time of landfall than perpendicular ones. Hence, the present study over the NIO endorses the findings over the Atlantic Ocean. Further, the TC with climatological/straight moving tracks usually move with normal speed, whereas, the recurving tracks move rapidly after the recurvature leading to large time error in landfall forecast. This fact has also been established by Powell and Aberson (2001) for landfalling TCs over the Atlantic Ocean. According to them, within $55 \mathrm{hr}$ of predicted landfall, slow-moving storms have 10\%-50\% smaller mean LPEs.

\subsection{Landfall forecast error with respect to specific regions of landfall}

To find out the errors and biases with respect to different regions of landfall, we have considered the landfalling TCs over the BOB only, as further stratification of the TCs for different geographical regions for the AS TCs leads to a very small sample size for analysis. The landfalling TCs over the BOB have been stratified to TCs landfalling over (i) Sri Lanka/Tamil Nadu (TN), (ii) Andhra Pradesh, (iii) Odisha/West Bengal, (iv) Bangladesh, and (v) Myanmar. As there is no landfall over Thailand and there were only two landfalls over Odisha and West Bengal during the period of study, the results are analysed for the specific regions of (i), (ii), (iv) and $(\mathrm{v})$.

The statistics of LPE and LTE for the landfalling TCs over the above specific regions are presented in figure 6. It is observed that the LPE and LTE generally increase from Sri Lanka/TN coasts in the south to Bangladesh/Myanmar coasts in the north. While the 24-hr LPE for Sri Lanka/TN is about
$67 \mathrm{~km}$, it is $195 \mathrm{~km}$ for Myanmar coast. Comparing the LPEs for TCs crossing different regions, they are significantly different at $90 \%$ confidence level for Sri Lanka/TN and AP coasts for 60-72-hr forecasts, Sri Lanka/TN and Myanmar coasts at 95\% confidence level for 12-hr forecasts, Myanmar and Bangladesh coasts at $90 \%$ confidence level for 12-hr forecasts. Comparing the LTEs, the difference is significant at $95 \%$ confidence level for AP-Bangladesh coast for 36-48-hr forecasts, TN and Bangladesh coasts at 90\% level for 24-36-hr forecasts. It may be due to the fact that, the TCs making landfall over southern latitude usually have straight/climatological tracks, whereas, the TCs making landfall over northern latitude like Bangladesh/Myanmar have recurving tracks. The recurving tracks have more LPEs and LTEs than those of straight moving tracks as discussed in previous section.

\subsection{Landfall forecast error with respect to intensity of TCs}

As the TCs intensify gradually, their location and intensity estimation becomes more accurate with well developed characteristic features of TCs such as eye, central dense overcast (CDO) and curve band features (IMD 2003, 2013). It results in more accurate location and intensity estimation over the open seas using satellite techniques. With more accurate determination of location and intensity, the accuracy of track forecasts increases in NWP models (Mohanty et al. 2010; Osuri et al. 2011) and hence the official landfall forecast accuracy increases. Hence, to verify the impact of intensity of TCs at the time of initialization of models and official forecast on the landfall forecast, the TCs have been classified into three categories of intensity, 


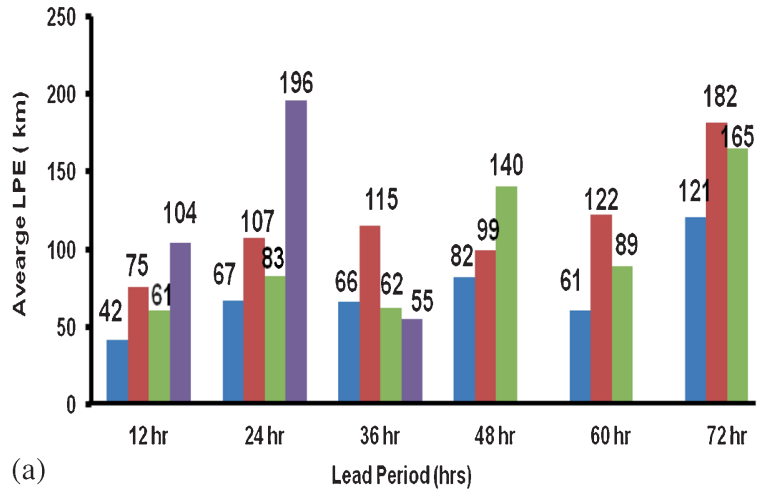

- Mean LPE/LTE for TCs crossing TN/Sri Lanka coast - Mean LPE/LTE for TCs crossing AP coast

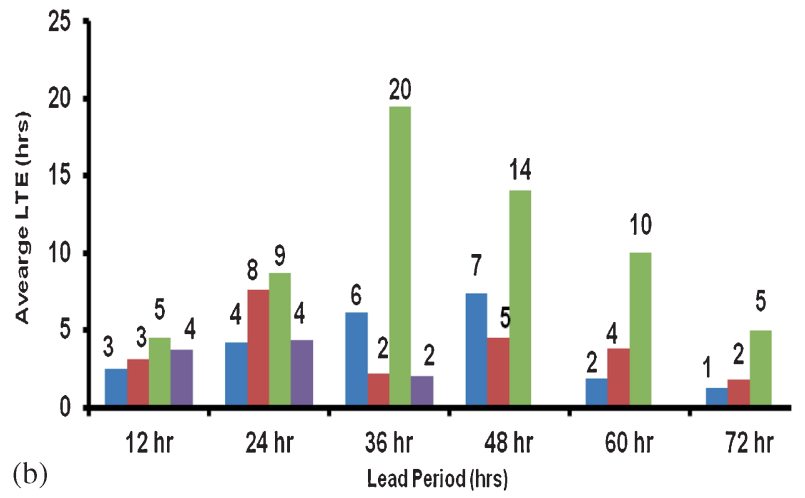

Mean LPE/LTE for TCs crossing Bangladesh coast - Mean LPE/LTE for TCs crossing Myanmar coast

Figure 6. (a) Average landfall point forecast error (LPE) and (b) average landfall time forecast error (LTE) for TCs crossing Tamil Nadu (TN)/Sri Lanka, Andhra Pradesh (AP), Bangladesh and Myanmar coasts.
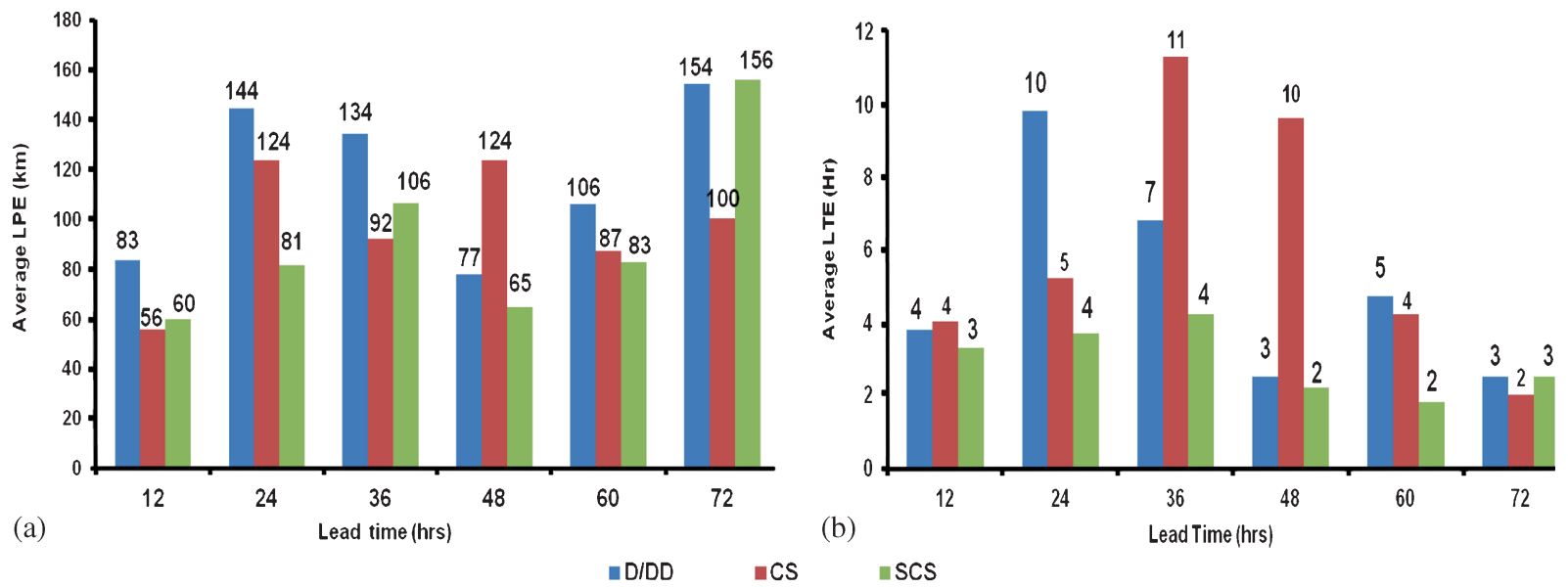

Figure 7. (a) Average landfall point forecast error (LPE) and (b) average landfall time forecast error (LTE) for D/DD, CS and SCS or higher intensity at the time of initialization of forecast.

viz., (i) depression/deep depression (D/DD), (ii) CS (maximum surface wind speed of 34-47 knots) and (iii) SCS or higher intensity (48 knots or more) at the time of initialization of forecast. The definition of the TCs analysed here is same as that adopted by $\operatorname{IMD}(2003,2013)$. There are 7,13 , and 13 TCs with intensity of D/DD, CS, and SCS or higher intensity respectively at the time of initialization of forecast during 2003-2013 (figure 1). There are 27, 40, and 40 cases of landfall forecasts for different forecast lengths (table 2) for TCs with intensity of D/DD, CS, and SCS or higher intensity respectively at the time of initialization of forecast. The statistics of LPEs and LTEs are shown in figure 7. With respect to intensity, the LPEs are in general higher in case of D/DD than in case of CS for all forecast lengths except for $48 \mathrm{hrs}$. It is higher in case of 48-hr forecast of the TC with intensity of CS at initial condition. However, as it can be seen from table 2, the number of forecast cases considered for study of $48 \mathrm{hrs}$ forecast is very less to draw the above conclusion. Similar is the situation considering the 72-hr forecast error of TCs with intensity of SCS at the time of initiation of forecast. The LTEs are also less for SCS than for D/DD or CS. However, according to Student's $t$ test, the LPE for SCS is significantly less than that for D/DD for 24-hr forecast and LPE of SCS is significantly less than that for CS for 48-hr forecast only. Similarly, the LTE for D/DD is higher than that of CS/SCS at $95 \%$ confidence level for 24-hr forecast only. Hence, it can be concluded that the landfall error is less with higher intensity of the TC at the time of initiation of 24 and $48-\mathrm{hr}$ forecasts. It is almost in agreement with the fact found earlier by Mohapatra et al. (2013a) that the track forecast error is less in case of SCS or higher intensity TCs compared to that of CS. According to Powell and Aberson (2001), within $55 \mathrm{hr}$ of predicted landfall, mean LPEs are slightly smaller for strong storms than for weak ones, though the difference is not statistically significant. 
Comparing the errors during 2003-2008 and 2009-2013, there is significant improvement in forecast during 2009-2013 with reduction of LTE of SCS at 90\% confidence level for 12-hr forecasts and of D/DD and CS at $95 \%$ confidence level for 24-hr forecasts.

\subsection{Landfall forecast error with respect to season of formation of TCs}

There are 13 and 20 landfalls of TCs in premonsoon and post-monsoon seasons respectively considered in the study (figure 1, tables 1-2). There are 41 and 66 cases of TC landfall forecasts for different forecast lengths (table 2) for TCs in premonsoon and post-monsoon seasons respectively during this period of study. The statistics of LPE and LTE are shown in figure 8 for the TCs in premonsoon and post-monsoon seasons. It is found that the LPE is less in case of TCs during postmonsoon season. The LPE varies from $68 \mathrm{~km}$ for 12-hr forecast to $101 \mathrm{~km}$ for 72 -hr forecast during post-monsoon season. Considering the LTE (figure 8b), it is also less in post-monsoon season than in pre-monsoon season. It varies between 2 and $7 \mathrm{hrs}$ for different forecast times. However, the difference in error is statistically significant at 90\% level for LTE only and for 12 and 36-hr forecasts. The higher accuracy during post-monsoon season may be attributed to the fact that the percentage of climatological/straight moving TCs are more in post-monsoon than in pre-monsoon season (figure 1, table 1). Out of 13 landfalls of TCs, eight $(62 \%)$ are recurving/looping type in pre-monsoon season, whereas 8 out of $20(40 \%)$ landfalls of TCs are recurving/looping type in post-monsoon season. The straight moving TCs are more in postmonsoon season and less in pre-monsoon season due to prevailing basic steering flow pattern in the middle and upper troposphere and the different location of Inter Tropical Convergence Zone (ITCZ), which is mainly responsible for TC genesis over the NIO. While the ITCZ lies in relatively southern latitude near about $10^{\circ} \mathrm{N}$ in the month of October/November, it lies to the north of $15^{\circ} \mathrm{N}$ in the month of April-June. Due to the genesis of the TCs in the lower latitude in OctoberDecember (IMD 2008), their track is not affected by the middle/upper tropospheric middle latitude trough in westerlies over the NIO region. On the other hand, during the months of April-June, the tracks of the TC very often get influenced by the mid-latitude westerly trough approaching from the west and extending sometimes to the south of $20^{\circ} \mathrm{N}$ latitude. As a result, these TCs recurve towards the northeast (Rao 1976). As discussed in the previous section (3.3), the accuracy in landfall forecast is more in case of climatological/straight moving than in case of recurving/looping TCs. The above findings are in agreement with the results obtained by Mohapatra et al. (2012c, 2013a) with respect to variation in track forecast errors during pre-monsoon and post-monsoon seasons. It is mainly due to limitation of the NWP models in correctly predicting the recurving tracks of TCs. Further, Osuri et al. (2012) have demonstrated with the WRF model that the model track forecast accuracy is less in case of recurving TCs than in case of straight moving TCs over NIO.

Comparing the mean LPEs during 2003-2008 and 2009-2013, there is significant improvement in forecast with reduction of LPE for both 12 and 24hr forecasts during 2009-2013 for the TCs during pre-monsoon season at $95 \%$ and $90 \%$ confidence level respectively. Also there is significant decrease at $95 \%$ confidence level in $24 \mathrm{hr}$ LPE and LTE during 2009-2013 for TCs in post-monsoon season.
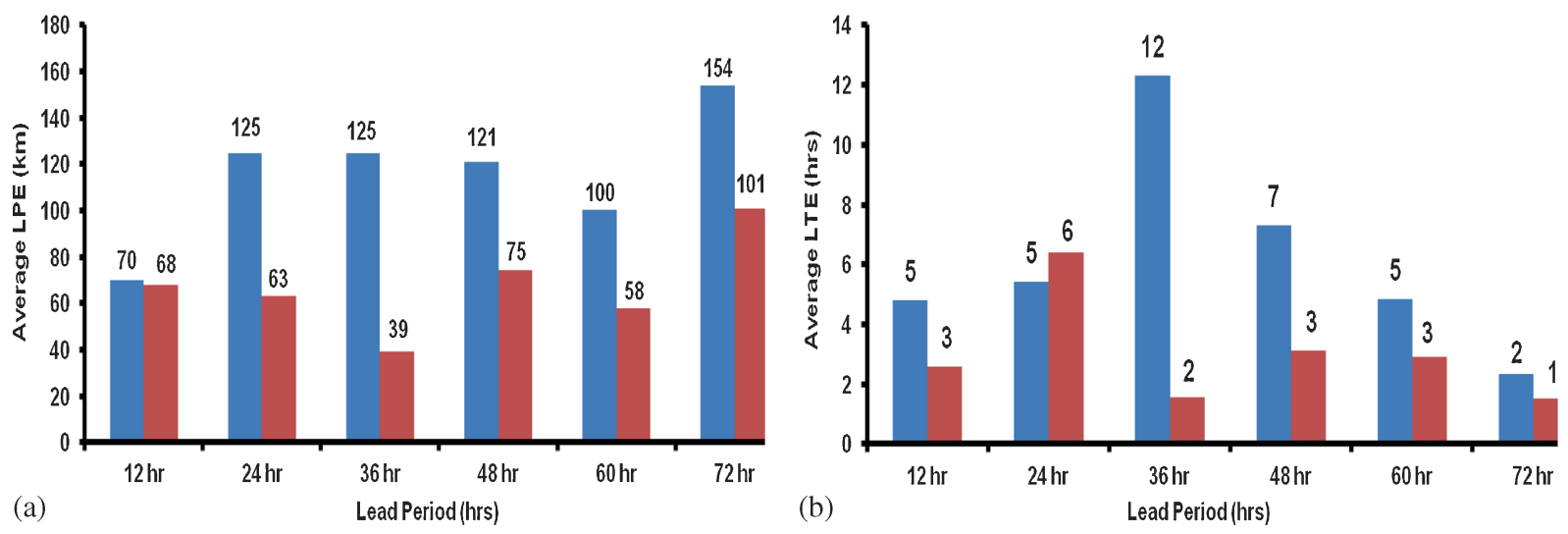

- Mean LPE/LTE during pre-monsoon season

- Mean LPE/LTE during post-monsoon season

Figure 8. (a) Average landfall point forecast error (LPE) and (b) average landfall time forecast error (LTE) for TCs during pre-monsoon and post-monsoon seasons over the NIO based on data of 2003-2013. 


\subsection{Interannual variation in landfall forecast error of $T C$}

Verification of TC landfall forecasts is important to evaluate the year on year improvement (or otherwise). Hence, the interannual variation in TC landfall forecast for 12 and 24-hr lead periods has been analysed based on annual LPE and LTE. The interannual variation for the lead period of $36-72 \mathrm{hrs}$ is not presented in this study, as the period of data is small (only 5 years, 2009-2013). The results are shown in figure 9 . It is found that the LPE decreased significantly during the period of study as evident in the trend lines. The improvement in landfall forecast (reduction in LPE) is about 31 and $14.5 \mathrm{~km}$ per year for 12 and 24 -hr forecasts respectively during 2003-2013, which are significant at $99 \%$ level of confidence (table 4). Mohapatra et al. (2013a) have found similar trend in reduction of track forecast errors, though the rate of decrease is higher in case of LPE. The track forecast error decreased by about 5.9 and $7.3 \mathrm{~km}$ per year for 12 and 24-hr forecasts respectively during 2003-2011 (Mohapatra et al. 2013a). There is also improvement in 12-hr landfall time forecast at the rate of $0.4 \mathrm{hr} /$ year, which is significant at $95 \%$ level of confidence and no significant trend in 24-hr landfall time forecast. Powell and Aberson (2001) based on TCs of 1976-2000, which crossed United States have shown an improvement trend in LPE for the 31-54-hr lead period but the fit fails significance testing at the $95 \%$ level.

However, there is still scope for further reduction in land forecast error over the NIO to about $50 \mathrm{~km}$ in $48-\mathrm{hr}$ forecast based on the latest technology including aircraft reconnaissance, deployment of buoys, assimilation of more observational data from satellite and Doppler weather radars, etc., in the NWP models.

\section{Limitations and future scope}

The analysis is based on data of limited period, especially in the forecast range of $48-72 \mathrm{hrs}$ period. However, the results are very interesting and in agreement with the global trend during the same period. There are four types of landfall errors (Powell and Aberson 2001), which can be defined as (i) time and position errors between forecast and observed landfall as calculated in the present study, (ii) position error at time of landfall (a position error can be defined as the distance between the forecast and observed location at the time of landfall. In this case, the forecast position may lie over land or over the sea. As the error is calculated based on time of observed landfall, it is similar to direct position error or track forecast error), (iii) time and position of closest approach to the landfall point (the time and position of the closest
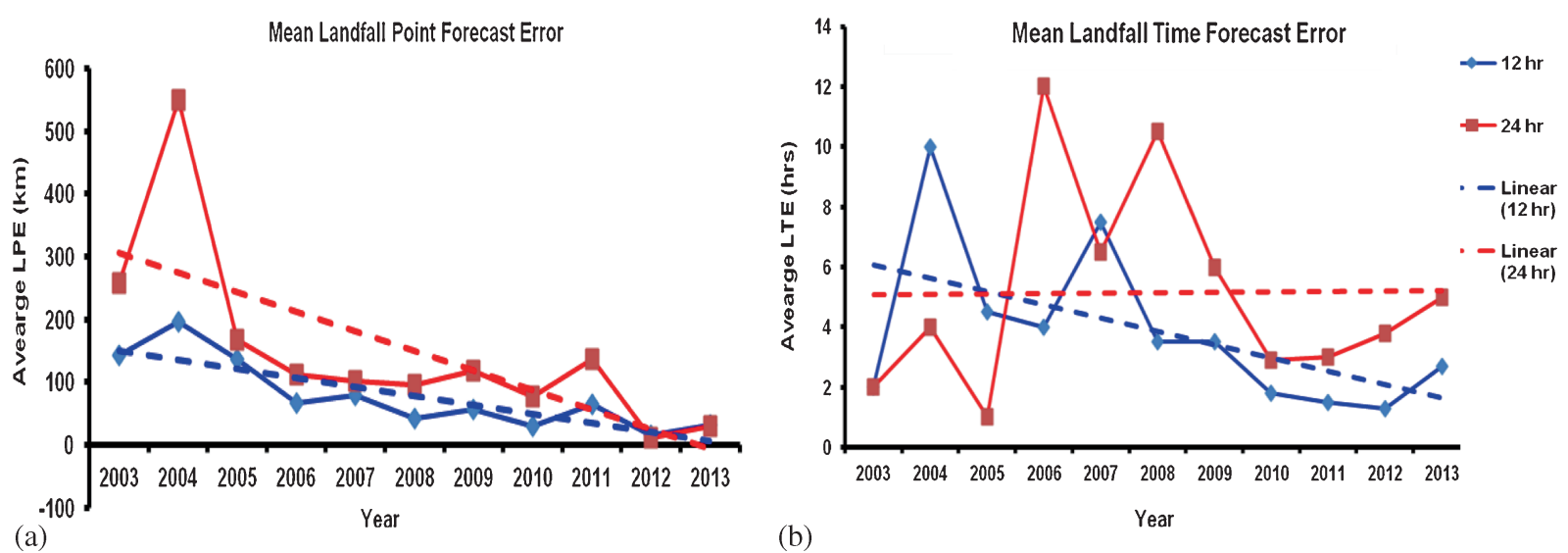

Figure 9. (a) Average landfall point forecast error (LPE) and (b) average landfall time forecast error (LTE) of IMD for TCs over the North Indian Ocean during 2003-2013.

Table 4. Average annual improvement per year (IMP), variance explained (Var), statistical significance (Sig.) of trend lines shown in figure 9 for the period of 2003-2013.

\begin{tabular}{lccccc}
\hline $\begin{array}{l}\text { Forecast } \\
\text { period }(\mathrm{hrs})\end{array}$ & $\begin{array}{c}\text { IMP in landfall } \\
\text { point forecast }(\mathrm{km})\end{array}$ & Variance $(\%)$ & $\begin{array}{c}\text { Sig. level of } \\
\text { trend line }\end{array}$ & $\begin{array}{c}\text { IMP in landfall } \\
\text { time forecast (hr) }\end{array}$ & $\begin{array}{c}\text { Sig. level of } \\
\text { Variance }(\%)\end{array}$ \\
\hline 12 & 14.5 & 72.2 & $99 \%$ & 0.44 & 29.6 \\
24 & 31.2 & 49.2 & $99 \%$ & -0.01 & 0.02 \\
\hline
\end{tabular}

NS: Not significant even at $90 \%$ level of confidence. 
approach of the interpolated forecast track to the observed landfall point defines this error measure), (iv) position error at time of forecast landfall (the position error between the observed and forecast locations of the $\mathrm{TC}$ at the interpolated forecast landfall time can also be computed). The present study has not included other measures of landfall forecast as mentioned above in SN (ii-iv). These aspects are being dealt with in separate studies.

Whenever a TC approaches land, more weightage is given to observations than to forecast positions and time of landfall. In such a case, 24-hr LTE should be less than 72-hr LTE. However, this fact is not brought out in the study as 72-hr LTE is less than 24-hr LTE. The LTEs of the NWP models (figure 3b), especially the MME and ECMWF, which are mainly used for operational forecasts are also less for $72 \mathrm{hrs}$ than for 24 -hr forecasts. It may be due to the fact that number of cases under consideration to calculate 72 -hr forecast error is very less (table 2). Hence, further study with longer data period is essential to achieve more consistent result.

\section{Conclusions}

The average LPE is about 67,95 , and $124 \mathrm{~km}$ and LTE is about 4, 7, and 2 hrs respectively for 24,48 , and 72-hr forecasts over the NIO as a whole during 2009-2013.

The accuracy of TC track forecasts has also been analysed with respect to basin of formation (BOB, $\mathrm{AS}$ and NIO as a whole), specific regions of landfall, season of formation (March-May and OctoberDecember), intensity of TCs (CS and SCS or higher intensities) at the time of initiation of forecast and type of track of TCs (climatological/straight moving and recurving/looping type). The LPE is less over the BOB than over the AS for all forecast lengths up to $72 \mathrm{hrs}$. Similarly, the LPE is less during the post-monsoon season than during premonsoon season. The LPE is less for climatologically moving/straight moving TCs than for the recurving/looping TCs. The LPE is significantly less with higher intensity of TC at the time of initiation of 24 and 48-hr forecast only and vice versa and LTE is less for 24-hr forecast only. Comparing different results, the types of track and intensity are the crucial factors in determining the LPE and LTE.

The LPE over the NIO has decreased at the rate of about $14.5 \mathrm{~km} /$ year during 2003-2013 for 24 -hr forecasts. The LTE does not show any significant improvement for $24-\mathrm{hr}$ forecast during the same period. There is significant decrease in LPE and LTE during 2009-2013 compared to 20032008 due to modernisation programme of IMD and other initiatives. The 24-hr LPE and LTE have decreased from 157.5 to $66.5 \mathrm{~km}$ and 7.8 to $4.1 \mathrm{hrs}$, respectively. However, there is still scope for further reduction in 48 and 72-hr forecast errors over the NIO to about 50 and $100 \mathrm{~km}$ respectively based on the latest technology including aircraft reconnaissance, deployment of buoys, and assimilation of more observational data from satellite and Doppler weather radars, etc., in the NWP models during next five years.

\section{Acknowledgements}

The authors are thankful to Director General of Meteorology, IMD for his support and encouragement to carry out this work. They are also thankful to Cyclone Warning Division for collection of data required for this work. They also thank the anonymous reviewers for their comments for improvement of the paper.

\section{References}

Fraedrich K and Leslie M 1989 Estimates of cyclone track predictability. I: Tropical cyclones in the Australian region; Quart. J. Roy. Meteor. Soc. 115 79-92.

IMD 2003 Cyclone Manual; IMD, New Delhi.

IMD 2008 Track of storm and depressions over the Indian seas during 1891-2007, 'Cyclone e-Atlas of IMD'; IMD, Chennai.

IMD 2013 Cyclone Warning in India: Standard Operation Procedure; IMD, New Delhi.

Mohanty U C, Osuri Krishna K, Routray A, Mohapatra M and Pattanayak Sujata 2010 Simulation of Bay of Bengal Tropical Cyclones with WRF Model: Impact of initial and boundary condition; Marine Geodesy 33 294-314.

Mohapatra M, Mandal G S, Bandyopadhyay B K, Tyagi A and Mohanty U C 2012a Classification of cyclone hazard prone districts of India; Natural Hazards 63(3) 1601-1620.

Mohapatra M, Bandyopadhyay B K and Tyagi Ajit 2012b Best track parameters of tropical cyclones over the North Indian Ocean: A review; Natural Hazards 63 1285-1317, doi: 10.1007/s11069-011-9935-0.

Mohapatra M, Nayak D P and Bandyopadhyay B K 2012c Evaluation of cone of uncertainty in tropical cyclone track forecast over North Indian Ocean issued by India Meteorological Department; Tropical Cyclone Research and Review $1331-339$.

Mohapatra M, Nayak D P, Sharma R P and Bandyopadhyay B K 2013a Evaluation of official tropical cyclone track forecast over North Indian Ocean issued by India Meteorological Department; J. Earth Syst. Sci. 122 589-601.

Mohapatra M, Sikka D R, Bandyopadhyay B K and Tyagi A 2013b Outcomes and challenges of forecast demonstration project (FDP) on landfalling cyclones over the Bay of Bengal; Mausam 64 1-12.

NHC USA 2012 Forecast verification report, National Oceanic and Atmospheric Administration, http://www. nhc.noaa.gov/verification.

Neumann C J and Pelissier J M 1981 An analysis of Atlantic tropical cyclone forecast errors, 1970-1979; Mon. Wea. Rev. 109 1248-1265.

Osuri Krishna K, Mohanty U C, Routray A and Mohapatra M 2011 The impact of satellite-derived wind data 
assimilation on track, intensity and structure of tropical cyclones over the North Indian Ocean; Int. J. Remote Sens., doi: 10.1080/01431161.2011.596849.

Osuri Krishna, Mohanty U C, Routray A and Mohapatra M 2012 Real-time Track Prediction of Tropical Cyclones over the North Indian Ocean using the ARW model; J. Appl. Meteorol. Climatol., doi: 10.1175/JAMC-D-12-0313.1.

Plu Matthieu 2011 A new assessment of the predictability of tropical cyclone tracks; Mon. Wea. Rev. 139 3600-3608.

Powell M D and Aberson S D 2001 Accuracy of United States tropical cyclone landfall forecasts in the Atlantic basin (1976-2000); Bull. Am. Meteor. Soc. 82 2749-2767.
Rao Y P 1976 Southwest Monsoon, Met Monograph, IMD, No. 1/1976, 335p.

RSMC New Delhi 2010 Report on Cyclonic Disturbances Over The North Indian Ocean During 2009; IMD, New Delhi.

RSMC New Delhi 2013 Report on Cyclonic Disturbances Over The North Indian Ocean During 2012; IMD, New Delhi.

RSMC Tokyo 2011 Annual Report on activities of the RSMC Tokyo Typhoon Center; http://www.jma.go.jp/ rsmc-hp-pub-eg/annualreport.html.

Simpson R H 1971 The decision process in hurricane forecasting; NOAA Tech Memo NWS SR-53, 33p.

MS received 3 June 2014; revised 18 December 2014; accepted 4 January 2015 